\title{
L-type amino acid transporter 1 expression is highly correlated with Gleason score in prostate cancer
}

\author{
ATSUKI SEGAWA $^{1,2}$, SHUSHI NAGAMORI ${ }^{3}$, YOSHIKATSU KANAI ${ }^{3}$, \\ NOBUHIDE MASAWA ${ }^{2}$ and TETSUNARI OYAMA ${ }^{1}$ \\ ${ }^{1}$ Department of Diagnostic Pathology, Gunma University Graduate School of Medicine, Maebashi, Gunma 371-8512; \\ ${ }^{2}$ Department of Pathology, Dokkyo University School of Medicine, Mibu, Tochigi 321-0293; \\ ${ }^{3}$ Division of Bio-system Pharmacology, Department of Pharmacology, Osaka University \\ Graduate School of Medicine, Suita, Osaka 565-0871, Japan
}

Received August 2, 2012; Accepted December 14, 2012

DOI: $10.3892 / \operatorname{mco} .2012 .54$

\begin{abstract}
Upregulation of L-type amino acid transporter 1 (LAT1), a member of the system L amino acid transporter family, may be detected by immunohistochemical methods. Immunoreactive LAT1 expression in prostate cancer is considered to be a promising biomarker for high-grade malignancy. However, the mutual association between LAT1 and Gleason score, the most fixed indicator for grading the malignancy of prostate cancers, remains to be elucidated. The aim of this study was to clarify the correlations between LAT1 and other factors in prostate cancer, including the Gleason score. We evaluated 54 cases of primary prostate cancer, surgically resected without any neoadjuvant therapies and performed immunohistochemistry for LAT1, Ki-67, CD34 and vascular endothelial growth factor on the tissue sections. The Gleason score as well as the age, pathological stage (pStage) of prostate cancer and serum concentration of prostate-specific antigen (PSA) of each case were also assessed. Statistical analysis for the correlations between LAT1 expression and Gleason score and each of the other characteristics studied was performed. As a result, a strong significant correlation between immunoreactive LAT1 expression and Gleason score was identified $(\mathrm{P}<0.01)$. We concluded that immunoreactive LAT1 expression in tissue sections of prostate cancer may be useful as a biomarker for high-grade malignancy.
\end{abstract}

\section{Introduction}

Prostate cancers have recently increased with regard to the number of patients and the mortality rate (1). L-type amino

Correspondence to: Dr Atsuki Segawa, Department of Diagnostic Pathology, Gunma University Graduate School of Medicine, Maebashi, Gunma 371-8512, Japan

E-mail: asegawa@med.gunma-u.ac.jp

Key words: biomarker, Gleason score, immunohistochemistry, L-type amino acid transporter 1, prostate cancer acid transporter 1 (LAT1) is a $\mathrm{Na}^{+}$-independent amino acid transporter responsible for system $\mathrm{L}$, a major nutrient transport system for large neutral amino acids $(2,3)$. Previous studies have shown that LAT1 is often excessively expressed in primary human neoplasms of various organs and is involved in tumor cell proliferation due to its function in transporting essential amino acids (4-6). Previous studies have demonstrated the upregulation of LAT1 immunohistochemically in prostate cancers (7), as well as in squamous cell carcinomas $(8,9)$, gliomas (10), urothelial carcinomas (11), non-small cell lung cancers $(12,13)$, breast cancers (14) and pancreatic cancers (15). In their previous study, Sakata et al (7) suggested that elevated LAT1 expression in prostate cancer core needle biopsy samples may be considered a novel biomarker for high-grade malignancy, but did not clarify the correlation between LAT1 expression and Gleason score, the most commonly used tool for grading the malignancy of prostate cancers. In the present study, to examine the associations between LAT1 expression and certain clinicopathological features, and to further evaluate the significance of LAT1 expression in prostate cancer, we retrospectively reviewed a total of 54 patients with surgically resected primary prostatic adenocarcinoma, and conducted immunohistological examinations for LAT1, Ki-67 labeling index (LI), CD34-positive microvessel density (MVD) and vascular endothelial growth factor (VEGF). Age, preoperative serum concentration of prostate-specific antigen (PSA), pathological stage (pStage) of cancer and Gleason score were also assessed for each patient.

\section{Materials and methods}

Patients. Fifty-four patients with primary prostatic adenocarcinoma who underwent radical prostatectomy in the Dokkyo Medical University Hospital (Tochigi, Japan) between January, 1999 and March, 2010 with no neoadjuvant therapies were evaluated in this study. Using the surgically resected tumor specimen of each patient, we determined the pStage using the TNM Classification of Malignant Tumours Seventh Edition of the International Union Against Cancer (UICC TNM 2009) (16) and the Gleason score, according to the guidelines of the 2005 
International Society of Urological Pathology consensus conference (17). The study protocol was approved by our institutional review board.

Immunohistochemical staining. We performed immunohistochemical staining for LAT1 (anti-human monoclonal mouse antibody 4A2, $2 \mu \mathrm{g} / \mathrm{ml}$; kindly provided by $\mathrm{Dr} \mathrm{H}$. Endou, J-Pharma Co., Ltd., Tokyo, Japan), Ki-67 (monoclonal mouse antibody MIB-1, 1:50; Dako Cytomation, Carpinteria, CA, USA), CD34 (monoclonal mouse antibody NU-4A1, ready-to-use; Nichirei Biosciences, Tokyo, Japan) and VEGF (monoclonal mouse antibody R11, 1:100; Immuno-Biological Laboratories Co., Ltd., Fujioka, Japan) using 4- $\mu \mathrm{m}$ formalin-fixed paraffin-embedded tissue sections from the surgically resected tumor samples of the 54 patients. Deparaffinization of the sections was performed by passage through xylene, while endogenous peroxidase activity was blocked with $1 \% \mathrm{H}_{2} \mathrm{O}_{2}$ in methanol for 30 min and antigen retrieval was performed with microwave pretreatment in citrate buffer if required (LAT1: $0.01 \mathrm{~mol} / \mathrm{l}, \mathrm{pH} 6.0,95^{\circ} \mathrm{C}$,

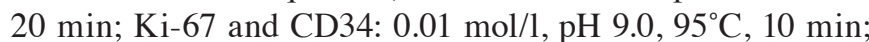
VEGF: no antigen retrieval techniques required). After rinsing in $0.01 \mathrm{~mol} / 1$ phosphate-buffered saline (PBS), $\mathrm{pH} 7.4$, and treatment with a protein blocking agent (Ultra Tech HRP Streptavidin-Biotin Detection System; Beckman Coulter, Fullerton, CA, USA) for $10 \mathrm{~min}$, the sections were incubated with each primary antibody for $2 \mathrm{~h}$ in humidity chambers at room temperature. After a thorough wash with PBS, the sections were incubated with a biotinylated secondary antibody (Ultra Tech HRP Streptavidin-Biotin Detection System) for $10 \mathrm{~min}$, followed by a streptavidin-peroxidase reagent (Ultra Tech HRP Streptavidin-Biotin Detection System) for an additional 10 min. 3,3'-Diaminobenzidine tetrahydrochloride (Nichirei Biosciences, Inc.) was used for visualization. The sections were then lightly counterstained with hematoxylin.

Immunohistochemical evaluation. LAT1 expression was considered positive only when the cell membranes of cancer cells showed obvious immunoreactivity (Fig. 1), since Sakata et al (7) demonstrated that LAT1 was localized on the cell membranes of cancer cells. Western blot analysis and absorption testing performed in a previously published study (7) clearly showed the specificity of monoclonal antibody $4 \mathrm{~A} 2$ for the N-terminal of the LAT1 peptide, and the good stability of 4A2 for immunohistochemistry on formalin-fixed and paraffin-embedded tissue sections (7).

We counted $\sim 1,000$ nuclei in a highly cellular area of each Ki-67-immunoreactive section of the 54 cases and defined positive cancer cells as those with nuclear immunoreactivity of any intensity. We assessed the proliferative activity as the percentage of immunopositive nuclei in the 1,000 cancer cells, representing the so-called $\mathrm{Ki}-67 \mathrm{LI}$ (18).

On the basis of the criteria of Weidner et al (19), we assessed the potential for invasion as MVD in the tumor areas showing the highest number of discrete microvessels positively stained for CD34. Any brown-stained endothelial cell or cell cluster that was clearly separated from adjacent microvessels, tumor cells and other connective tissue elements was considered to be a single countable microvessel. The
A

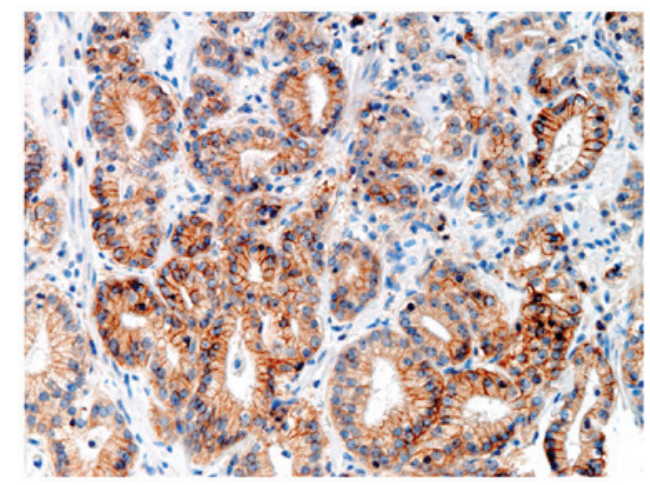

B

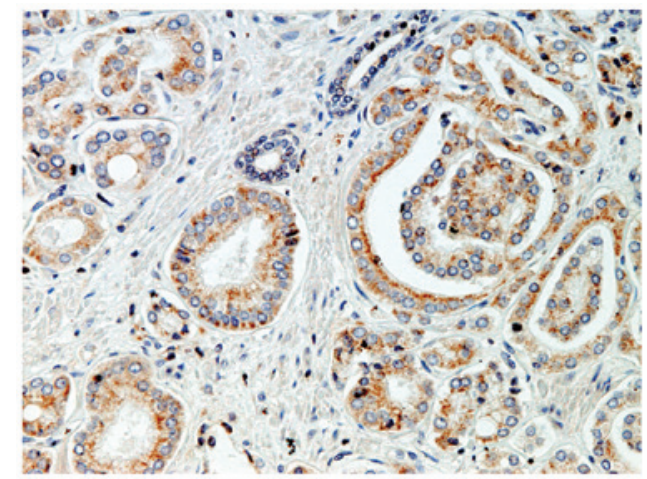

C

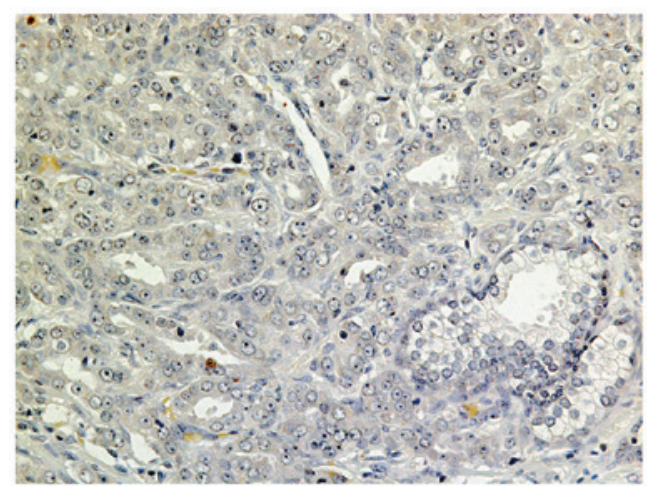

Figure 1. Immunohistochemical findings of prostate cancer for L-type amino acid transporter 1 (LAT1). LAT1 expression was considered positive only when (A) the cell membranes of cancer cells showed obvious immunoreactivity. (B) Intracytoplasmic staining and (C) obscure reactivity were regarded as negative.

number of CD34-positive vessels in a x400 field $\left(0.26 \mathrm{~mm}^{2}\right.$ field area) was counted at four selected hotspots and the MVD was defined as the mean count of microvessels $/ 0.26 \mathrm{~mm}^{2}$ field area.

VEGF expression was assessed according to the percentage of immunoreactive cells in a total of 1,000 neoplastic cells (quantitative analysis) (20).

The Gleason score determination and immunohistochemical evaluation of each antibody were separately performed by two board-certified pathologists. In cases of discrepancy, the sections were simultaneously inspected by the two pathologists until they reached agreement for the final assessment.

Statistical analysis. The Mann-Whitney U test was used to assess the association between two factors comprising LAT1 
Table I. Patient characteristics $(n=54)$.

\begin{tabular}{|c|c|c|c|c|c|c|c|c|}
\hline No. & LAT1 & Gleason score & pStage & $\begin{array}{c}\text { PSA } \\
(\mathrm{ng} / \mathrm{ml})\end{array}$ & $\begin{array}{c}\text { Age } \\
\text { (years) }\end{array}$ & $\begin{array}{c}\text { Ki-67 LI } \\
(\%)\end{array}$ & $\begin{array}{l}\text { CD34 } \\
\text { MVD }\end{array}$ & $\begin{array}{c}\text { VEGF } \\
(\%)\end{array}$ \\
\hline 1 & Positive & $5+4=9$ & 4 & 6.5 & 69 & 9.1 & 12 & 100 \\
\hline 2 & Positive & $4+5=9$ & 3 & 6.6 & 74 & 1.8 & 40 & 28 \\
\hline 3 & Positive & $4+5=9$ & 3 & 6.5 & 64 & 0.1 & 18 & 0 \\
\hline 4 & Positive & $4+4=8$ & 3 & 8.9 & 64 & 0 & 30 & 0 \\
\hline 5 & Positive & $3+5=8$ & 3 & 6.7 & 64 & 3.6 & 33 & 73 \\
\hline 6 & Positive & $3+5=8$ & 3 & 5.9 & 61 & 0.1 & 38 & 0 \\
\hline 7 & Positive & $4+3=7$ & 3 & 15.6 & 66 & 0 & 28 & 100 \\
\hline 8 & Positive & $4+3=7$ & 3 & 11.5 & 72 & 2.2 & 62 & 0 \\
\hline 9 & Positive & $4+3=7$ & 3 & 8.0 & 64 & 1.5 & 19 & 100 \\
\hline 10 & Positive & $4+3=7$ & 2 & 12.9 & 69 & 5.9 & 24 & 100 \\
\hline 11 & Positive & $4+3=7$ & 2 & 10.4 & 61 & 0.4 & 28 & 8 \\
\hline 12 & Positive & $4+3=7$ & 2 & 4.2 & 72 & 6.3 & 38 & 100 \\
\hline 13 & Positive & $3+4=7$ & 2 & 5.1 & 60 & 0.2 & 28 & 42 \\
\hline 14 & Negative & $4+5=9$ & 3 & 4.9 & 72 & 0.1 & 58 & 0 \\
\hline 15 & Negative & $4+5=9$ & 2 & 12.1 & 68 & 0.1 & 33 & 85 \\
\hline 16 & Negative & $4+4=8$ & 3 & 35.8 & 77 & 6.7 & 24 & 35 \\
\hline 17 & Negative & $4+4=8$ & 2 & 9.4 & 69 & 2.8 & 18 & 83 \\
\hline 18 & Negative & $3+5=8$ & 3 & 6.2 & 60 & 4.6 & 18 & 100 \\
\hline 19 & Negative & $4+3=7$ & 3 & 17.0 & 51 & 0.9 & 20 & 60 \\
\hline 20 & Negative & $4+3=7$ & 3 & 13.3 & 73 & 1.9 & 33 & 55 \\
\hline 21 & Negative & $4+3=7$ & 3 & 13.1 & 63 & 2.1 & 24 & 0 \\
\hline 22 & Negative & $4+3=7$ & 3 & 5.7 & 64 & 3.8 & 16 & 75 \\
\hline 23 & Negative & $4+3=7$ & 3 & 5.1 & 57 & 3.1 & 32 & 0 \\
\hline 24 & Negative & $4+3=7$ & 3 & 3.7 & 61 & 0.2 & 20 & 11 \\
\hline 25 & Negative & $4+3=7$ & 2 & 11.8 & 71 & 2.5 & 28 & 100 \\
\hline 26 & Negative & $4+3=7$ & 2 & 10.5 & 67 & 0.6 & 29 & 0 \\
\hline 27 & Negative & $4+3=7$ & 2 & 6.2 & 59 & 0 & 30 & 100 \\
\hline 28 & Negative & $3+4=7$ & 3 & 5.9 & 65 & 0.4 & 15 & 0 \\
\hline 29 & Negative & $3+4=7$ & 3 & 2.3 & 61 & 0.7 & 31 & 0 \\
\hline 30 & Negative & $3+4=7$ & 2 & 15.2 & 62 & 0 & 31 & 100 \\
\hline 31 & Negative & $3+4=7$ & 2 & 8.9 & 51 & 0.2 & 21 & 0 \\
\hline 32 & Negative & $3+4=7$ & 2 & 8.8 & 75 & 1.1 & 16 & 63 \\
\hline 33 & Negative & $3+4=7$ & 2 & 8.6 & 73 & 5.4 & 33 & 44 \\
\hline 34 & Negative & $3+4=7$ & 2 & 8.6 & 58 & 0.5 & 18 & 100 \\
\hline 35 & Negative & $3+4=7$ & 2 & 8.5 & 73 & 0.1 & 30 & 0 \\
\hline 36 & Negative & $3+4=7$ & 2 & 7.0 & 54 & 2 & 32 & 100 \\
\hline 37 & Negative & $3+4=7$ & 2 & 5.5 & 66 & 0.1 & 21 & 12 \\
\hline 38 & Negative & $3+4=7$ & 2 & 4.2 & 72 & 1 & 57 & 0 \\
\hline 39 & Negative & $3+4=7$ & 1 & 5.3 & 75 & 0.8 & 17 & 0 \\
\hline 40 & Negative & $3+3=6$ & 3 & 11.5 & 64 & 0 & 16 & 47 \\
\hline 41 & Negative & $3+3=6$ & 3 & 11.0 & 65 & 0.2 & 27 & 15 \\
\hline 42 & Negative & $3+3=6$ & 3 & 10.3 & 59 & 0.1 & 16 & 0 \\
\hline 43 & Negative & $3+3=6$ & 3 & 7.2 & 66 & 0.1 & 18 & 75 \\
\hline 44 & Negative & $3+3=6$ & 3 & 1.7 & 74 & 8.2 & 13 & 88 \\
\hline 45 & Negative & $3+3=6$ & 2 & 24.5 & 68 & 1.4 & 17 & 67 \\
\hline 46 & Negative & $3+3=6$ & 2 & 5.8 & 66 & 3.4 & 21 & 67 \\
\hline 47 & Negative & $3+3=6$ & 2 & 5.7 & 74 & 1 & 22 & 44 \\
\hline 48 & Negative & $3+3=6$ & 2 & 4.5 & 63 & 0 & 31 & 27 \\
\hline 49 & Negative & $3+3=6$ & 2 & 4.1 & 73 & 3.6 & 17 & 0 \\
\hline 50 & Negative & $3+3=6$ & 2 & 4.1 & 72 & 0.5 & 30 & 10 \\
\hline
\end{tabular}


Table I. Continued.

\begin{tabular}{lccccccc}
\hline No. & & & PSA & Age & Ki-67 LI & $\begin{array}{c}\text { CD34 } \\
(\%) \\
\text { MVD }\end{array}$ & $\begin{array}{c}\text { VEGF } \\
(\%)\end{array}$ \\
\hline 51 & Negative & $3+3=6$ & 2 & 3.8 & 68 & 0.7 & 39 \\
52 & Negative & $3+3=6$ & 2 & 3.8 & 61 & 0.1 & 25 \\
53 & Negative & $3+3=6$ & 1 & 8.1 & 61 & 0.4 & 15 \\
54 & Negative & $3+3=6$ & 1 & 4.0 & 63 & 0.1 & 14 \\
\hline
\end{tabular}

LAT1, L-type amino acid transporter 1; pStage, pathological stage; PSA, prostate-specific antigen; LI, labeling index; MVD, microvessel density; VEGF, vascular endothelial growth factor.

Table II. Associations between LAT1 expression and clinicopathological parameters in patients with prostate cancer.

\begin{tabular}{|c|c|c|c|}
\hline Variables & LAT1-positive & LAT1-negative & P-value \\
\hline \multicolumn{4}{|l|}{ Gleason score } \\
\hline$\geq 8$ and $4+3=7$ & 12 & 14 & \multirow[t]{2}{*}{$<0.01$} \\
\hline$\leq 6$ and $3+4=7$ & 1 & 27 & \\
\hline \multicolumn{4}{|c|}{ Pathological stage } \\
\hline$\geq \mathrm{III}$ & 9 & 16 & \multirow[t]{2}{*}{0.059} \\
\hline$\leq \mathrm{II}$ & 4 & 25 & \\
\hline \multicolumn{4}{|c|}{ Age (years) (cut-off: 65.5 years) } \\
\hline$\geq 66$ & 6 & 21 & \multirow[t]{3}{*}{0.75} \\
\hline$\leq 65$ & 7 & 20 & \\
\hline Median/range & $64 / 60-74$ & $66 / 51-77$ & \\
\hline \multicolumn{4}{|c|}{ Serum PSA (ng/ml) (cut-off: $10 \mathrm{ng} / \mathrm{ml})$} \\
\hline$>10$ & 4 & 12 & \multirow[t]{3}{*}{0.92} \\
\hline$\leq 10$ & 9 & 29 & \\
\hline Median/range & $6.7 / 4.2-15.6$ & 7.0/1.7-35.8 & \\
\hline \multicolumn{4}{|c|}{ Ki-67 labeling index (\%) (cut-off: $1.0 \%$ ) } \\
\hline$>1.0$ & 7 & 15 & \multirow[t]{3}{*}{0.27} \\
\hline$\leq 1.0$ & 6 & 26 & \\
\hline Median/range & $1.5 / 0.0-9.1$ & $0.7 / 0.0-8.2$ & \\
\hline \multicolumn{4}{|c|}{ MVD by CD34-positivity (cut-off: MVD 24.5) } \\
\hline$\geq$ MVD 25 & 9 & 18 & \multirow[t]{3}{*}{0.12} \\
\hline$\leq$ MVD 24 & 4 & 23 & \\
\hline Median/range & $28 / 12-62$ & $22 / 13-58$ & \\
\hline \multicolumn{4}{|c|}{ VEGF (\%) (cut-off: $31.5 \%$ ) } \\
\hline$\geq 32$ & 7 & 20 & \multirow[t]{3}{*}{0.75} \\
\hline$\leq 31$ & 6 & 21 & \\
\hline Median/range & $42 / 0.0-100$ & $27 / 0.0-100$ & \\
\hline
\end{tabular}

LAT1, L-type amino acid transporter 1; PSA, prostate-specific antigen; MVD, microvessel density; VEGF, vascular endothelial growth factor.

expression, Gleason score and other clinicopathological characteristics listed in Table I. $\mathrm{P}<0.05$ was considered to indicate a statistically significant difference. Statistical analysis was performed using StatView version 4.54 for the Windows software (SAS Institute Inc., Cary, NC, USA).

\section{Results}

Patient characteristics. Characteristics of the 54 patients enrolled in the present study are listed in Table I. Patient age ranged from 51 to 77 years (median, 65.5 years), and the 
Table III. Associations between Gleason score and clinicopathological parameters in patients with prostate cancer.

\begin{tabular}{|c|c|c|c|}
\hline Variables & $\mathrm{GS} \geq 8$ or $4+3=7$ & $\mathrm{GS} \leq 6$ or $3+4=7$ & P-value \\
\hline \multicolumn{4}{|l|}{ LAT1 } \\
\hline Positive & 12 & 1 & \multirow[t]{2}{*}{$<0.01$} \\
\hline Negative & 14 & 27 & \\
\hline \multicolumn{4}{|c|}{ Pathological stage } \\
\hline$\geq \mathrm{III}$ & 18 & 7 & \multirow[t]{2}{*}{$<0.01$} \\
\hline$\leq \mathrm{II}$ & 8 & 21 & \\
\hline \multicolumn{4}{|c|}{ Age (years) (cut-off: 65.5 years) } \\
\hline$\geq 66$ & 13 & 14 & \multirow[t]{3}{*}{1.00} \\
\hline$\leq 65$ & 13 & 14 & \\
\hline Median/range & $65.0 / 51-77$ & $65.5 / 51-75$ & \\
\hline \multicolumn{4}{|c|}{ Serum PSA (ng/ml) (cut-off: 10 ng/ml) } \\
\hline$>10$ & 11 & 5 & \multirow[t]{3}{*}{0.051} \\
\hline$\leq 10$ & 15 & 23 & \\
\hline Median/range & $8.5 / 3.7-35.8$ & $5.9 / 1.7-24.5$ & \\
\hline \multicolumn{4}{|c|}{ Ki-67 labeling index (\%) (cut-off: $1.0 \%$ ) } \\
\hline$>1.0$ & 15 & 7 & \multirow[t]{3}{*}{0.016} \\
\hline$\leq 1.0$ & 11 & 21 & \\
\hline Median/range & $1.85 / 0.0-9.1$ & $0.45 / 0.0-8.2$ & \\
\hline \multicolumn{4}{|c|}{ MVD by CD34-positivity (cut-off: MVD 24.5) } \\
\hline$\geq$ MVD 25 & 15 & 12 & \multirow[t]{3}{*}{0.28} \\
\hline$\leq \mathrm{MVD} 24$ & 11 & 16 & \\
\hline Median/range & $28 / 12-62$ & $21 / 13-57$ & \\
\hline \multicolumn{4}{|c|}{ VEGF (\%) (cut-off: $31.5 \%)$} \\
\hline$\geq 32$ & 15 & 12 & \multirow[t]{3}{*}{0.28} \\
\hline$\leq 31$ & 11 & 16 & \\
\hline Median/range & $57.5 / 0.0-100$ & $13.5 / 0.0-100$ & \\
\hline
\end{tabular}

GS, Gleason score; LAT1, L-type amino acid transporter 1; PSA, prostate-specific antigen; MVD, microvessel density; VEGF, vascular endothelial growth factor.

median value was considered to be the cut-off point. For the preoperative serum PSA concentration, the range was 1.7 to $35.8 \mathrm{ng} / \mathrm{ml}$ (median, $6.9 \mathrm{ng} / \mathrm{ml}$ ). We determined the cut-off point for serum PSA at $10.0 \mathrm{ng} / \mathrm{ml}$, according to the D'Amico risk assessment (21). We found that $16(30 \%)$ of 54 patients had higher PSA concentrations compared to the cut-off value. The pStage distribution by the TNM classification was as follows: pStage I or II, n=29; pStage III or IV, $n=25$. Since the Gleason score is well-known to be markedly correlated with lethal risk for patients following treatment, we divided the 54 patients into two groups, comprising a high (Gleason score of $4+3=7$, $\geq 8$ ) and a low GS group (Gleason score $3+4=7, \leq 6$ ), according to the findings of previously published studies (21-23). Overall, 26 patients were in the high and 28 patients in the low GS group.

Immunohistochemical analysis. Of the 54 patients, 13 (24\%) exhibited positive LAT1 immunoreactivity. Expression of LAT1 was not observed in non-neoplastic prostate epithelium. The median values of Ki-67 LI, MVD determined by CD34-positivity, and VEGF expression were $0.7 \%$ (range,
0.0-9.1), 24.5 (range, 12-62) and 31.5\% (range, 0.0-100), respectively. The cut-off point of $\mathrm{Ki}-67 \mathrm{LI}$ was set at $1.0 \%$, based on the findings of a previously published study by Laitinen et al (24). For MVD, by CD34-positivity, and VEGF expression, each median value was chosen as the cut-off point. Of the 54 patients, expression higher than the cut-off value was respectively identified in $22(41 \%)$ patients for $\mathrm{Ki}-67 \mathrm{LI}$, $27(50 \%)$ patients for MVD by CD34-positivity and 27 (50\%) patients for VEGF expression.

Associations between LATl expression and other factors. The associations between LAT1 expression and other factors are shown in Table II. Overall, 12 of 13 LAT1-positive cases belonged to the high GS group, and a significant correlation was clearly observed between LAT1 expression and Gleason score $(\mathrm{P}<0.01)$. LAT1 expression showed a tendency for more occasional expression in cases with a higher pStage $(\mathrm{P}=0.059)$, but was not markedly associated with age, serum PSA, Ki-67 LI, MVD by CD34-positivity or VEGF expression.

In the 13 cases with positive LAT1 immunoreactivity, the positively stained cancer cells were mainly distributed on 
invasive borders, rather than inside tumor cell clusters. The predominant histological forms of the prostate cancers at the LAT1-positive areas varied among the 13 cases with no statistically significant difference (trabecular pattern in two cases, fused glands in nine cases, and single-shaped glands in two cases).

Associations between Gleason score and other factors. The associations between Gleason score and other factors are shown in Table III. The Gleason score was significantly correlated with LAT1 expression $(\mathrm{P}<0.01)$, pStage $(\mathrm{P}<0.01)$, and Ki-67 LI $(\mathrm{P}=0.016)$. The serum PSA concentration tended to be higher in the patients in the high GS group $(\mathrm{P}=0.051)$. No statistically significant correlations were detected between Gleason score and age, or MVD by CD34-positivity or VEGF expression.

\section{Discussion}

LAT1 is a $\mathrm{Na}^{+}$-independent amino acid transporter with 12 putative membrane-spanning domains $(25,26)$, and its activity is essential for tumor cell proliferation in various organs including the prostate (7-15). Sakata et al (7) suggested that LAT1 expression in a prostate cancer may be regarded as a strongly significant prognostic factor for the patient and that an immunoreactive LAT1 expression test has potential as a biomarker indicating high-grade malignancy of prostate cancers. When prostate cancers are assessed for their degree of malignancy, the Gleason score is the most commonly used parameter worldwide. However, a great discrepancy remains, since no statistically significant correlation between immunoreactive LAT1 expression and Gleason score has been detected in studies conducted by Sakata et al (7). Gleason scores were grouped using individual scores from 5 to 10 , while urologists and pathologists usually divide the Gleason scores into two or three groups: low and high GS groups, or low, middle, and high GS groups (21-23). We estimated that this could be the reason why Sakata et al (7) did not demonstrate a significant association between LAT1 expression and Gleason score. In the present study, we have clearly demonstrated this significant correlation, after adequately grouping the Gleason scores into two groups. To the best of our knowledge, the present study is the first to markedly correlate immunoreactive LAT1 expression and the monoclonal antibody 4A2 with the Gleason score, showing that LAT1 is reliable as a biomarker for high-grade prostate cancers.

The Gleason score was also significantly correlated with the pStage of the patients and Ki-67 LI on tissue sections and an almost significant association was found between serum PSA and Gleason score, while LAT1 expression did not show statistically significant correlations with any of the pStage, Ki-67 LI or serum PSA. Age and MVD by CD34-positivity and VEGF expression showed no statistically significant correlations with LAT1 expression or Gleason score, although Kaira et al (20) reported statistically significant correlations between LAT1 and MVD by CD34-positivity and VEGF expression for primary lung adenocarcinomas. This discrepancy may occur as prostate cancers usually exhibit a slower growth compared to lung cancers. In other studies, lung adenocarcinomas and breast cancers showed much more intense and clearer immunoreactivity on the cell membranes
$(14,20)$ compared to the prostate adenocarcinomas discussed in this study. This discrepancy may also occur due to the relatively gentle character of prostate cancers. However, a pale stain in the tissue sections prepared, may have resulted from inferiority in certain technical skills.

The LAT1-positive cancer cells appeared to be mainly distributed on invasive borders, rather than inside tumor cell clusters, suggesting that LAT1 is involved in the infiltration of tumor cells into interstitial tissues.

We conclude that LAT1 expression in prostate cancer tissue sections is a promising biomarker for high-grade malignancy. However, the reliability of LAT1 is not likely to exceed that of the Gleason score. Although the Gleason grading system is more reliable compared to the LAT1 immunoreactivity, LAT1 may nevertheless be as useful as the Gleason score, since testing for immunoreactive LAT1 expression is relatively simple and the results are easy to interpret, while the Gleason grading system requires a sufficient number of skilled pathologists for proper application in a population.

\section{Acknowledgements}

The authors are deeply grateful to Dr Hitoshi Endou (J-Pharma Co., Ltd.) for providing the anti-LAT1 antibody. The authors are also greatly indebted to Mr. S Suzuki and Mr. H Kojima (Dokkyo Medical University, Tochigi, Japan) for their excellent technical assistance.

\section{References}

1. Matsuda T and Saika K: Comparison of time trends in prostate cancer incidence (1973-2002) in Asia, from cancer incidence in five continents, Vols IV-IX. Jpn J Clin Oncol 39: 468-469, 2009.

2. Kanai Y, Segawa H, Miyamoto K, Uchino H, Takeda E and Endou H: Expression cloning and characterization of a transporter for large neutral amino acids activated by the heavy chain of 4F2 antigen (CD98). J Biol Chem 273: 23629-23632, 1998.

3. Meier C, Ristic Z, Klauser S and Verrey F: Activation of system L heterodimeric amino acid exchangers by intracellular substrates. EMBO J 21: 580-589, 2002.

4. Yanagida O, Kanai Y, Chairoungdua A, et al: Human L-type amino acid transporter 1 (LAT1): characterization of function and expression in tumor cell lines. Biochim Biophys Acta 1514: 291-302, 2001

5. Fuchs BC and Bode BP: Amino acid transporters ASCT2 and LAT1 in cancer: partners in crime? Semin Cancer Biol 15: 254-266, 2005.

6. Yamauchi K, Sakurai H, Kimura T, Wiriyasermkul P, Nagamori S, Kanai Y and Kohno N: System L amino acid transporter inhibitor enhances anti-tumor activity of cisplatin in a head and neck squamous cell carcinoma cell line. Cancer Lett 276: 95-101, 2009.

7. Sakata T, Ferdous G, Tsuruta T, et al: L-type amino-acid transporter 1 as a novel biomarker for high-grade malignancy in prostate cancer. Pathol Int 59: 7-18, 2009.

8. Kim DK, Ahn SG, Park JC, et al: Expression of L-type amino acid transporter 1 (LAT1) and 4F2 heavy chain (4F2hc) in oral squamous cell carcinoma and its precursor lesion. Anticancer Res 24: 1671-1675, 2004.

9. Kobayashi H, Ishii Y and Takayama T: Expression of L-type amino acid transporter 1 (LAT1) in esophageal carcinoma. J Surg Oncol 90: 233-238, 2005.

10. Nawashiro H, Otani N, Shinomiya N, et al: L-type amino acid transporter 1 as a potential molecular target in human astrocytic tumors. Int J Cancer 119: 484-492, 2006.

11. Nakanishi K, Ogata S, Matsuo H, et al: Expression of LAT1 predicts risk of progression of transitional cell carcinoma of the upper urinary tract. Virchows Arch 451: 681-690, 2007. 
12. Kaira K, Oriuchi N, Imai H, et al: Prognostic significance of L-type amino acid transporter 1 expression in resectable stage I-III non-small cell lung cancer. Br J Cancer 98: 742-748, 2008.

13. Takeuchi K, Ogata S, Nakanishi K, et al: LAT1 expression in non-small cell lung carcinomas: analyses by semiquantitative reverse transcription-PCR (237 cases) and immunohistochemistry (295 cases). Lung Cancer 68: 58-65, 2010.

14. Furuya M, Horiguchi J, Nakajima H, Kanai Y and Oyama T: Correlation of L-type amino acid transporter 1 and CD98 expression with triple negative breast cancer prognosis. Cancer Sci 103: 382-389, 2012.

15. Kaira K, Sunose Y, Segawa A, et al: Prognostic significance of L-type amino acid transporter 1 expression in surgically resected pancreatic cancer. Br J Cancer 107: 632-638, 2012.

16. Sobin LH, Gospodarowicz MK and Wittekind C (eds): TNM Classification of Malignant Tumors (UICC International Union Against Cancer). 7th edition. Wiley-Blackwell, Oxford, 2009.

17. Epstein JI, Allsbrook WC Jr, Amin MB, Egevad LL and ISUP Grading Committee: The 2005 International Society of Urological Pathology (ISUP) consensus conference on Gleason grading of prostatic carcinoma. Am J Surg Pathol 29: 1228-1242, 2005.

18. Buck AC, Schirrmeister HH, Guhlmann CA, et al: Ki-67 immunostaining in pancreatic cancer and chronic active pancreatitis: does in vivo FDG uptake correlate with proliferative activity? J Nucl Med 42: 721-725, 2001.

19. Weidner N, Semple JP, Welch WR and Folkman J: Tumor angiogenesis and metastasis - correlation in invasive breast carcinoma. N Engl J Med 324: 1-8, 1991.
20. Kaira K, Oriuchi N, Imai H, et al: Prognostic significance of L-type amino acid transporter 1 (LAT1) and 4F2 heavy chain (CD98) expression in stage I pulmonary adenocarcinoma. Lung Cancer 66: 120-126, 2009.

21. D'Amico AV, Whittington R, Malkowicz SB, et al: Biochemical outcome after radical prostatectomy, external beam radiation therapy, or interstitial radiation therapy for clinically localized prostate cancer. JAMA 280: 969-974, 1998.

22. Stark JR, Perner S, Stampfer MJ, et al: Gleason score and lethal prostate cancer: does 3+4=4+3? J Clin Oncol 27: 3459-3464, 2009.

23. Wright JL, Salinas CA, Lin DW, Kolb S, Koopmeiners J, Feng Z and Stanford JL: Prostate cancer specific mortality and Gleason 7 disease differences in prostate cancer outcomes between cases with Gleason $4+3$ and Gleason $3+4$ tumors in a population-based cohort. J Urol 182: 2702-2707, 2009.

24. Laitinen S, Martikainen PM, Tolonen T, Isola J, Tammela T and Visakorpi T: EZH2, Ki-67 and MCM7 are prognostic markers in prostatectomy-treated patients. Int J Cancer 122: 595-602, 2008.

25. Mastroberardino L, Spindler B, Pfeiffer R, et al: Amino-acid transport by heterodimers of $4 \mathrm{~F} 2 \mathrm{hc} / \mathrm{CD} 98$ and members of a permease family. Nature 395: 288-291, 1998.

26. Kim DK, Kanai Y, Matsuo H, et al: The human T-type amino acid transporter-1: characterization, gene organization, and chromosomal location. Genomics 79: 95-103, 2002. 